Research article

Open Access

\title{
Basal-like grade III invasive ductal carcinoma of the breast: patterns of metastasis and long-term survival
}

\author{
Laura G Fulford ${ }^{1,2}$, Jorge S Reis-Filho ${ }^{1}$, Ken Ryder ${ }^{3}$, Chris Jones ${ }^{4}$, Cheryl E Gillett ${ }^{3}$, \\ Andrew Hanby ${ }^{5}$, Douglas Easton ${ }^{6}$ and Sunil R Lakhani1,7
}

\author{
${ }^{1}$ Breakthrough Breast Cancer Research Centre, The Institute of Cancer Research, Fulham Road, London, SW3 6JB, UK \\ 2The Ludwig Institute for Cancer Research, 91 Riding House Street, London W1W 7BS, UK \\ ${ }^{3}$ Hedley Atkins/Imperial Cancer Research Fund Breast Pathology Laboratory, Guy's Hospital, London, SE1 9RT, UK \\ ${ }^{4}$ The Institute of Cancer Research, Fulham Road, London, SW3 6JB, UK \\ ${ }^{5}$ Academic Unit of Pathology, Leeds University c/o St James' University Hospital, Beckett Street, Leeds, LS9 7TF, UK \\ ${ }^{6}$ Cancer Research Campaign Genetic Epidemiology Unit, Strangeways Research Laboratory, Worts Causeway, Cambridge, CB1 8RN, UK \\ ${ }^{7}$ Molecular and Cellular Pathology, School of Medicine, The University of Queensland, and Queensland Institute of Medical Research, $300 \mathrm{Herston}$ \\ Road, Herston, Brisbane, 4006, Australia
}

Corresponding author: Laura G Fulford, laura.work@gmail.com

Received: 6 Oct 2006 Revisions requested: 14 Nov 2006 Revisions received: 8 Dec 2006 Accepted: 11 Jan 2007 Published: 11 Jan 2007

Breast Cancer Research 2007, 9:R4 (doi:10.1186/bcr1636)

This article is online at: http://breast-cancer-research.com/content/9/1/R4

(c) 2007 Fulford et al.; licensee BioMed Central Ltd.

This is an open access article distributed under the terms of the Creative Commons Attribution License (http://creativecommons.org/licenses/by/2.0), which permits unrestricted use, distribution, and reproduction in any medium, provided the original work is properly cited.

\begin{abstract}
Introduction Cytokeratin (CK) 14, one of several markers expressed in normal myoepithelial/basal cells, is also expressed in a proportion of breast carcinomas. Previous studies have suggested that expression of such 'basal' markers predicts different biological behaviour, with more frequent lung and brain metastases and poorer prognosis than other carcinomas.
\end{abstract}

Methods We performed CK14 immunohistochemistry on 443 grade III invasive ductal carcinomas with extended clinical follow-up (mean 116 months), and we correlated CK14 immunopositivity (basal-like phenotype) with clinicopathological criteria.

Results Eighty-eight of 443 (20\%) tumours showed CK14 expression. CK14-positive tumours were more likely to be oestrogen receptor-negative $(p<0.0001)$ and axillary nodenegative $(p=0.001)$ than were CK14-negative cases. CK14- positive cases developed less bone and liver metastases (hazard ratio [HR] $0.49, p=0.01$, and HR 0.53, $p=0.035$, respectively) but more frequent brain metastases (HR 1.92, $p=$ $0.051)$. In patients without metastatic disease, disease-free survival in CK14-positive cases was significantly better than in CK14-negative cases (HR 0.65, $p=0.005$ ). In patients with metastatic disease, however, CK14 positivity was associated with a poorer prognosis (HR 1.84, $p=0.001$ ). The overall survival in CK14-positive and -negative patients was similar at 5 years $(60 \%$ and $59 \%$, respectively), but the long-term survival was better in CK14-positive patients (HR 0.69, $p=0.02$ ).

Conclusion These results demonstrate that basal-like tumours differ in their biological behaviour from other tumours, with a distinct pattern of metastatic spread. Compared to other grade III tumours, basal-like tumours appear to have a relatively good long-term survival but survival after metastases is poor.

\section{Introduction}

Breast cancer is a common but very diverse disease with considerable survival heterogeneity [1-5]. An ongoing challenge is to find improved methods of identifying and classifying groups of tumours with differing biological behaviours or responsiveness to specific therapies. Expression profiling analysis is reshaping our understanding of breast cancer and has pro- vided a working model for modern breast cancer taxonomy [68]. These seminal studies have systematically identified a subgroup of breast tumours that are characterised by the expression of genes normally expressed in basal/myoepithelial cells of normal breast, including high-molecular-weight cytokeratins (CKs) and P-cadherin [6-10]. These findings have confirmed and expanded the concepts first described as early as 1967 [11], and in particular those described over the last decade [12], by conventional histopathological and

BRCA1 = breast cancer 1, early onset; $\mathrm{CGH}=$ comparative genomic hybridisation; $\mathrm{CK}=$ cytokeratin; $\mathrm{DFS}=$ disease-free survival; EIA = enzyme immunoassay; ER = oestrogen receptor; HER2 = C-erb B2 receptor; HR = hazard ratio; IDC-NST = invasive ductal carcinomas of no special type; $\mathrm{OR}=$ odds ratio; $\mathrm{OS}=$ overall survival; $\mathrm{PR}=$ progesterone receptor. 


\section{Figure 1}

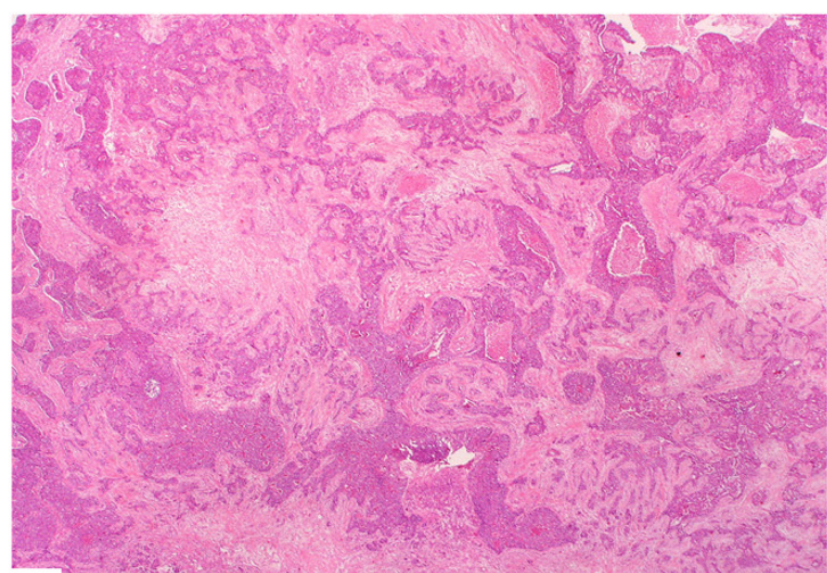

(a)

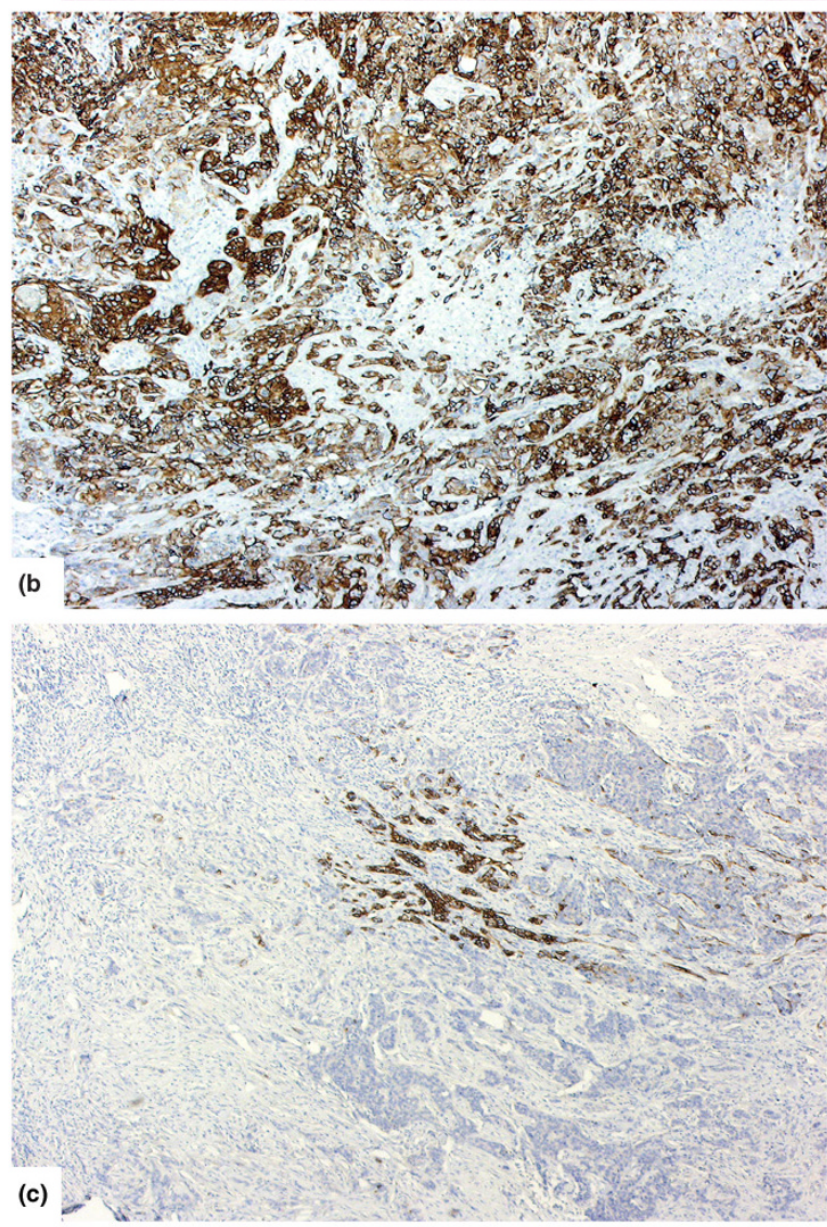

Histological appearance of basal tumours and CK14 expression patterns. (a) Typical histological appearance of a basal breast carcinoma (haematoxylin and eosin). (b) CK14 expression: a basal tumour with basal keratin expression in almost every tumour cell (diffuse staining pattern). (c) Another basal tumour with only a minority of tumour cells showing expression (focal staining pattern).

immunohistochemical examination. Studies have demonstrated that whilst most breast tumours express a purely luminal phenotype, a minority of ductal tumours ( $4 \%$ to $22 \%$ ) will show ultrastructural features and co-express markers that are characteristic of the outer myoepithelial, or basal, compartment of the normal breast [11-35].

Morphologically, these tumours are predominantly of high grade $[9,19,23-26,29,35]$ and more frequently show medullary-like features $[30,31]$ and metaplastic elements [19,20,32,33,36-39] (Figure 1a). Immunohistochemically, they are predominantly oestrogen receptor (ER)-, progesterone receptor (PR)-, and C-erb B2 receptor (HER2)-negative $[19,22,24,25,32]$. These characteristics also predominate among tumours arising in patients with germline BRCA1 (breast cancer 1 , early onset) mutations [40,41]. Recent studies have indicated that positive staining for 'basal' markers in patients with familial breast and/or ovarian tumours is strongly predictive of carrying a BRCA1 mutation [27,34,41]; however, there are several lines of evidence to suggest that sporadic basal-like ductal carcinomas do not harbour BRCA1 somatic mutations [42].

Despite these morphological, immunohistochemical, and molecular features, current routine diagnostic practice does not separately recognise these tumours and management is the same as for other grade- and stage-matched breast tumours. Importantly, however, evidence suggests that these tumours have a metastatic pattern of dissemination and clinical behaviour that are different than comparable ductal carcinomas not showing basal marker expression. Tsuda et al. [19] and Hicks et al. [43] reported a higher incidence of lung and brain metastases associated with a myoepithelial phenotype, as defined by CK14, smooth muscle actin, or $\mathrm{S} 100$ protein expression. Furthermore, retrospective, population-based studies have demonstrated that tumours that express these basal markers have a more aggressive clinical behaviour when compared to those with a luminal phenotype and that 'basal' status may be an independent prognostic factor. In contrast, a comparative genomic hybridisation $(\mathrm{CGH})$ analysis performed in our institutions [28] of 86 invasive ductal carcinomas of no special type (IDC-NST) (50\% CK14-positive and stage- and age-matched), all of which were grade III, did not suggest a uniformly poor prognosis for the basal-like (CK14-positive) tumours. Instead, the $\mathrm{CGH}$ analysis revealed distinct subgroups of basal-like grade III tumours that exhibited a comparatively good prognosis with extended clinical follow-up $(>10$ years), in comparison to the rest of the grade III group, and a basal-like subgroup with a relatively poor prognosis. In fact, in contrast to the 'pan-grade' studies, the CK14-positive tumours appeared to have an overall better outcome than the rest of the group [28].

To investigate these observations further and explore the hypothesis that basal-like tumours are entities biologically distinct from other ductal carcinomas and that they may themselves have different subgroups, we assessed a large cohort 
of grade III IDC-NST for expression of CK14 and correlated this with long-term survival and pattern of metastatic disease.

\section{Materials and methods}

Four hundred and seventy grade III IDC-NST, diagnosed between 1975 and 1991, were identified from the patient database at the Hedley Atkins/Imperial Cancer Research Fund Breast Pathology Laboratory, Guy's Hospital (London, UK), where all the cases were managed. Tumours had been graded according to the modified Bloom and Richardson system [2] and have been previously published [44]. Immunohistochemistry was performed on a single tumour block for CK14 as detailed previously [28,29]. Briefly, 2 minutes of pressurecooking at $\mathrm{pH} 6.0$ was used for antigen retrieval with CK14 clone LL002 (1:50) (BioGenex Inc., San Ramon, CA, USA). Four hundred and forty-three cases contained tumour on review.

CK14 expression was assessed independently by two pathologists (LGF and JSR-F). A tumour was designated as CK14positive if it was considered that at least $1 \%$ of true invasive tumour cells expressed the CK marker. From our previous experience $[28,29]$, and as recently demonstrated by Laakso et al. [25,26], it has been apparent that whereas in some tumours virtually every cell expresses the basal marker (CK14, in this instance), others may show a focal or variable percentage of positive cells (Figure 1b,c). We therefore subdivided the CK14-positive tumours into those showing 'diffuse expression' (defined as more than $90 \%$ of tumour cells positive; Figure $1 \mathrm{~b}$ ) and those showing 'focal expression' (1\% to $90 \%$ of cells positive; Figure 1c). Discrepancies between the observers were resolved on a multi-headed microscope. For ease of reading, CK14-positive tumours are referred to henceforth as 'basal' and CK14-negative tumours as 'non-basal' cases. Data on tumour size, axillary lymph node status, ER, and primary treatment were available for $98 \%, 98 \%, 93 \%$, and $100 \%$ of patients, respectively. Between 1975 and 1991, the methodology for ER measurement changed as newer reagents became available. Initially, ER status was determined by cytosol ligand-binding assay [45], which was then replaced by the Abbott enzyme immunoassay (EIA) (Abbott Laboratories, Abbott Park, IL, USA) [46]. A successful comparative study was undertaken between the ligand-binding assay and EIA before transferring to the latter method.

All ER data were recorded on a prospectively acquired and verified clinicopathological database at the time of assay. Full clinical follow-up data, including sites of metastatic disease, were available for all cases.

\section{Statistical analysis}

Associations between CK14 immunoreactivity and clinicopathological parameters-including tumour size (as defined by TMN [tumour-node-metastasis] staging, $5^{\text {th }}$ edition), tumour grade (modified Bloom-Richardson grading) [2], menstrual status, ER and PR status, presence of axillary lymph node metastases, local recurrence, and distant metastasis-were evaluated by Fisher's exact test or $\chi^{2}$ test as appropriate. Mean age at diagnosis and CK14 positivity were compared using a $t$ test.

Survival analyses were conducted for overall survival (OS), disease-free survival (DFS), survival to metastases at specific sites, and time from first recurrence to death. DFS was defined as time to any type of recurrence, distant metastasis, or death from any cause. Survival curves were calculated using the Kaplan-Meier method. Tests of differences in survival between groups were performed using the log-rank test and were expressed as hazard ratios (HRs), which were estimated using Cox regression. Cox regression analysis was also used to evaluate any independent effect of prognostic factors on DFS, $\mathrm{OS}$, and survival from recurrence. Factors significant at a $p$ value of less than 0.05 in the survival analysis, together with CK14 as the factor of principal interest, were included in the regression analyses. All tests were two-tailed, and 95\% confidence intervals are presented where appropriate. All analyses were carried out using Stata (version 7.0, StataCorp LP, Texas, USA).

\section{Results}

The distribution of clinicopathological features is detailed in Table 1. Briefly, age at diagnosis ranged from 21 to 85 years (mean 53.2 years). Fifty-seven percent of tumours had axillary nodal metastases, and $46 \%$ were ER-positive. Fifty-two percent of cases had received no form of adjuvant treatment. Length of follow-up ranged from 3.2 to 333.5 months, with a mean follow-up of 116.4 months.

\section{OS and DFS in the whole cohort}

Associations of potential prognostic factors with OS, DFS, and survival from first recurrence are shown in Table 2. As expected, both OS and recurrence-free survival were inversely related to the presence of axillary nodal metastases $(p<$ $0.0001)$ and primary tumour size $(p=0.003)$. Tumours occurring in women less than 35 years old or more than 65 years old at diagnosis had poorer OS and DFS than women 35 to 65 years old ( $p=0.002$ and $p=0.01$, respectively). ER- and PRnegative tumours showed a significantly poorer survival from first recurrence (HR 2.10, $p<0.0001$, and HR 1.51, $p=$ 0.005 , respectively). These features are entirely consistent with the outcomes expected in follow-up of such a group of grade III breast tumours.

\section{CK14 expression}

Of the 443 cases, 88 (20\%) showed CK14 expression and are considered to be 'basal' tumours. They occurred at a slightly, but significantly, younger age than other grade III tumours (mean 49.9 years versus 53.9 years, $p=0.0065$; Table 3$)$. They were more likely to be ER- and PR-negative (odds ratio [OR] 10.9, $p<0.0001$, and OR 11.9, $p<0.0001$, 
Table 1

Clinicopathological features of the cohort of $\mathbf{4 7 0}$ grade III invasive ductal carcinomas of no special type

\begin{tabular}{|c|c|}
\hline Parameter & Number \\
\hline \multicolumn{2}{|l|}{ Age in years } \\
\hline Range & 21-85 (mean 53.2) \\
\hline$<35$ & $36(8 \%)$ \\
\hline $35-50$ & $142(32 \%)$ \\
\hline $51-65$ & $189(43 \%)$ \\
\hline$>65$ & $76(17 \%)$ \\
\hline \multicolumn{2}{|l|}{ Menopausal status } \\
\hline Premenopausal & $175(40 \%)$ \\
\hline Perimenopausal & $64(15 \%)$ \\
\hline Postmenopausal & $195(45 \%)$ \\
\hline Unknown & 9 \\
\hline \multicolumn{2}{|l|}{ Tumour size } \\
\hline Range & $0.5-10.5 \mathrm{~cm}$ (mean $3.4 \mathrm{~cm})$ \\
\hline p1 & $27(6 \%)$ \\
\hline p2 & $313(72 \%)$ \\
\hline p3 & $93(21 \%)$ \\
\hline \multicolumn{2}{|l|}{ Axillary nodes } \\
\hline Positive & $251(57 \%)$ \\
\hline Negative & $184(42 \%)$ \\
\hline \multicolumn{2}{|l|}{ Oestrogen receptor } \\
\hline Positive & $191(46 \%)$ \\
\hline Negative & $222(54 \%)$ \\
\hline Not available & 30 \\
\hline \multicolumn{2}{|l|}{ Surgical management } \\
\hline None & $2(1 \%)$ \\
\hline Mastectomy & $318(72 \%)$ \\
\hline Tumourectomy & $123(28 \%)$ \\
\hline \multicolumn{2}{|l|}{ Adjuvant treatment } \\
\hline None & $229(52 \%)$ \\
\hline Tamoxifen/Ovarian oblation & $103(22 \%)$ \\
\hline Chemotherapy and tamoxifen & $5(1 \%)$ \\
\hline Chemotherapy & $112(25 \%)$ \\
\hline Length of follow-up in months & 3.2-333.5 (mean 116.4) \\
\hline
\end{tabular}

Tumour sizes: $\mathrm{p} 1,<2 \mathrm{~cm} ; \mathrm{p} 2,2-5 \mathrm{~cm} ; \mathrm{p} 3,>5 \mathrm{~cm}$.

respectively) and less likely to have axillary nodal metastases (OR 0.44, $p=0.0023$ ). There was no apparent correlation with tumour size or menopausal status.
Basal phenotype and effect on survival

Basal tumours exhibited a significantly better OS and DFS than non-basal tumours (HR 0.69, $p=0.02$, and HR 0.65, $p=$ 0.005 , respectively; Table 2 , Figure $2 a, b)$. DFS was similar in 
Table 2

\begin{tabular}{|c|c|c|c|c|c|c|c|c|}
\hline \multirow[t]{2}{*}{ Parameter } & \multicolumn{3}{|c|}{ Overall survival } & \multicolumn{3}{|c|}{ Disease-free survival } & \multicolumn{2}{|c|}{ Survival from recurrence } \\
\hline & 5-year & Hazard ratio $(95 \% \mathrm{Cl})$ & $p$ value & 5-year & Hazard ratio $(95 \% \mathrm{Cl})$ & $p$ value & Hazard ratio $(95 \% \mathrm{Cl})$ & $p$ value \\
\hline \multicolumn{9}{|c|}{ Axillary metastases } \\
\hline No & $71 \%$ & 1.0 & $<0.0001$ & $65 \%$ & 1.0 & $<0.0001$ & 1.0 & 0.32 \\
\hline Yes & $51 \%$ & $1.83(1.44-2.33)$ & & $41 \%$ & $1.83(1.45-2.32)$ & & $1.17(0.86-1.57)$ & \\
\hline \multicolumn{9}{|l|}{ Tumour size } \\
\hline $\mathrm{p} 1$ & $89 \%$ & 1.0 & 0.002 & $70 \%$ & 1.0 & 0.0005 & 1.0 & 0.26 \\
\hline p2 & $61 \%$ & $1.54(0.92-2.62)$ & & $54 \%$ & $1.49(0.90-2.48)$ & & $1.09(0.60-1.96)$ & \\
\hline p3 & $46 \%$ & $2.18(1.25-3.82)$ & & $35 \%$ & $2.20(1.28-3.79)$ & & $1.29(0.69-2.41)$ & \\
\hline \multicolumn{9}{|l|}{ ER } \\
\hline Positive & $64 \%$ & 1.0 & 0.68 & $52 \%$ & 1.0 & 0.74 & 1.0 & $<0.0001$ \\
\hline Negative & $52 \%$ & $1.05(0.83-1.33)$ & & $48 \%$ & $0.96(0.76-1.21)$ & & $2.1(1.59-2.79)$ & \\
\hline \multicolumn{9}{|l|}{ PR } \\
\hline Positive & $64 \%$ & 1.0 & 0.82 & $49 \%$ & 1.0 & 0.55 & 1.0 & 0.005 \\
\hline Negative & $56 \%$ & $1.03(0.80-1.33)$ & & $52 \%$ & $0.93(0.72-1.19)$ & & $1.51(1.13-2.02)$ & \\
\hline \multicolumn{9}{|l|}{ Age in years } \\
\hline$<35$ & $53 \%$ & 1.0 & 0.002 & $39 \%$ & 1.0 & 0.01 & 1.0 & 0.96 \\
\hline $35-50$ & $58 \%$ & $0.90(0.57-1.41)$ & & $50 \%$ & $0.99(0.63-1.55)$ & & $0.89(0.57-1.39)$ & \\
\hline $50-65$ & $64 \%$ & $0.81(0.52-1.26)$ & & $57 \%$ & $0.85(0.55-1.31)$ & & $0.89(0.57-1.38)$ & \\
\hline$>65$ & $54 \%$ & $1.44(0.90-2.30)$ & & $44 \%$ & $1.39(0.87-2.23)$ & & $0.89(0.52-1.50)$ & \\
\hline \multicolumn{9}{|l|}{ CK14 } \\
\hline Negative & $59 \%$ & 1.0 & 0.02 & $49 \%$ & 1.0 & 0.005 & 1.0 & 0.001 \\
\hline Positive & $60 \%$ & $0.69(0.50-0.94)$ & & $56 \%$ & $0.65(0.48-0.88)$ & & $1.84(1.27-2.65)$ & \\
\hline \multicolumn{9}{|c|}{ CK14 pattern } \\
\hline Negative & $59 \%$ & 1.0 & 0.005 & $49 \%$ & 1.0 & 0.003 & 1.0 & 0.002 \\
\hline Focal & $50 \%$ & $0.92(0.65-1.28)$ & & $48 \%$ & $0.83(0.59-1.16)$ & & $2.31(1.54-3.45)$ & \\
\hline Diffuse & $88 \%$ & $0.31(0.15-0.63)$ & & $79 \%$ & $0.32(0.17-0.63)$ & & $0.84(0.35-2.06)$ & \\
\hline
\end{tabular}

Tumour sizes: $\mathrm{p} 1,<2 \mathrm{~cm} ; \mathrm{p} 2,2-5 \mathrm{~cm} ; \mathrm{p} 3,>5 \mathrm{~cm}$. Cl, confidence interval; CK14, cytokeratin 14; ER, oestrogen receptor; PR, progesterone receptor.

basal and non-basal patients for the first 5 years after diagnosis (56\% in basal patients, $49 \%$ in non-basal patients) but then diverged (52\% versus $38 \%$ at 10 years). Similarly, the OS was almost identical during the first 5 years (60\% versus $59 \%$ ) but then diverged such that patients with basal tumours survived significantly longer (survival at 10 years $54 \%$ versus $43 \%$ ). The difference in survival remained when analyses were restricted to ER-negative tumours (HR 0.62, $p=0.01$, for OS; HR 0.63, $p=0.01$, for DFS). After adjustment for age, tumour size, and nodal metastases, DFS remained significantly better in basal cases (HR 0.72, $p=0.05)$ but the effect on OS was no longer significant (HR 0.78, $p=0.14$; Table 4).
Importantly, considering only breast tumours that relapsed, expression of basal markers was associated with significantly poorer prognosis. Survival after first recurrence was significantly shorter for basal tumours (HR 1.84, $p=0.001$; Figure $2 c)$. Interestingly, most of the recurrences seen in patients with basal tumours happened in the first 5 years of follow-up.

\section{CK14 expression patterns}

Of the 88 basal cases, 24 (27\%) fell into the diffuse staining category and the remaining 64 (73\%) showed focal CK14 expression (of these, half exhibited less than $50 \%$ tumour cell expression and the remainder between 50\% and 90\%). Both 
Table 3

\begin{tabular}{|c|c|c|c|c|}
\hline Parameter & Basal & Non-basal & Adjusted odds ratio & $p$ value \\
\hline \multicolumn{5}{|l|}{ Oestrogen receptor } \\
\hline Positive & $8(9 \%)$ & $183(52 \%)$ & & $<0.0001$ \\
\hline Negative & $72(81 \%)$ & $150(42 \%)$ & $10.9(5.08-23.2)$ & \\
\hline \multicolumn{5}{|c|}{ Progesterone receptor } \\
\hline Positive & $4(5 \%)$ & $122(33 \%)$ & & $<0.0001$ \\
\hline Negative & $75(85 \%)$ & $206(58 \%)$ & $11.9(4.2-33.6)$ & \\
\hline \multicolumn{5}{|l|}{ Axillary nodes } \\
\hline Positive & $37(42 \%)$ & $214(60 \%)$ & & 0.0023 \\
\hline Negative & $49(55 \%)$ & $135(38 \%)$ & $0.44(0.27-0.72)$ & \\
\hline \multicolumn{5}{|l|}{ Tumour size } \\
\hline p1 & $5(6 \%)$ & $22(6 \%)$ & 1.0 & 0.92 \\
\hline p2 & $66(75 \%)$ & $247(70 \%)$ & $1.41(0.50-3.97)$ & \\
\hline p3 & $17(19 \%)$ & $76(21 \%)$ & $1.19(0.38-3.7)$ & \\
\hline \multicolumn{5}{|l|}{ Menopausal status } \\
\hline Premenopausal & $42(47 \%)$ & $133(37 \%)$ & 1.0 & \\
\hline Perimenopausal & $15(17 \%)$ & $49(14 \%)$ & $1.91(0.71-5.19)$ & \\
\hline Postmenopausal & $33(38 \%)$ & $164(46 \%)$ & $1.31(3.80)$ & \\
\hline Mean age in years & 49.9 (SE 1.30) & 53.9 (SE 0.65) & & 0.0065 \\
\hline
\end{tabular}

Tumour sizes: $p 1,<2 \mathrm{~cm} ; \mathrm{p} 2,2-5 \mathrm{~cm} ; \mathrm{p} 3,>5 \mathrm{~cm}$. SE, standard error.

OS and DFS were significantly better for diffuse than for focal CK14 staining ( $p=0.012$ and $p=0.02$, respectively). Focally positive tumours had OS and DFS similar to the non-basal tumours, whereas the prognosis for diffuse staining was markedly better (Figure 2d,e). Survival from metastasis did not differ by staining pattern $(p=0.14)$, but this comparison had very limited power because there were only nine recurrences in the diffuse staining group (Figure 2f). Statistical analysis showed no difference in hormone status, tumour size, axillary nodal status, menopausal status, age, or local recurrence between tumours showing the two different patterns of staining (data not shown).

\section{Effect of treatment}

Because these tumours date from the 1970s, there was wide variation in treatments. Some patients received tamoxifen and/ or chemotherapy, whereas the majority received no systemic therapy, as was standard at that time. To investigate whether the differences in survival seen in the basal tumours may be related to the introduction of adjuvant therapies, we also analysed the subset of 229 patients who had received no adjuvant chemotherapy, hormonal therapy, or ovarian oblation. In this subset, basal tumours ( $n=52,23 \%)$ were still associated with a significantly improved OS (HR 0.50, $p=0.018$ ) and DFS (HR 0.48, $p=0.001$ ); however, this effect was not independent of the nodal status, because basal tumours are more often node-negative at presentation. These HRs were greater than for the cohort as a whole (tests for interaction, $p$ $=0.01$ for OS and $p=0.017$ for DFS). Among patients treated with adjuvant hormonal therapy, basal tumours were associated with a poorer survival (HR 1.76, 95\% confidence interval 0.94 to 3.29 ). This is likely to reflect the inverse correlation between expression of basal markers and hormone receptors and the impact of hormone therapy on the survival of patients with receptor-positive breast cancer.

\section{Basal tumours and sites of metastases}

There were clear differences in the development of metastases to specific sites between the basal and non-basal tumours (Table 5). Basal tumours were significantly less likely to develop bone $(p=0.01)$ or liver $(p=0.035)$ metastases or have involvement of non-regional lymph nodes $(p=0.008)$ but were more likely to develop brain metastases $(p=0.051)$. There was no difference in the rate of lung and pleu

ral metastases between the two groups.

\section{Discussion}

These data contrast with much of the recently published data showing entirely poor outcome in basal tumours $[7,8,10,17,33]$. Unlike that of previous pan-grade studies, the aim of this study was to look at the impact of 'basal' phenotype 
(a)

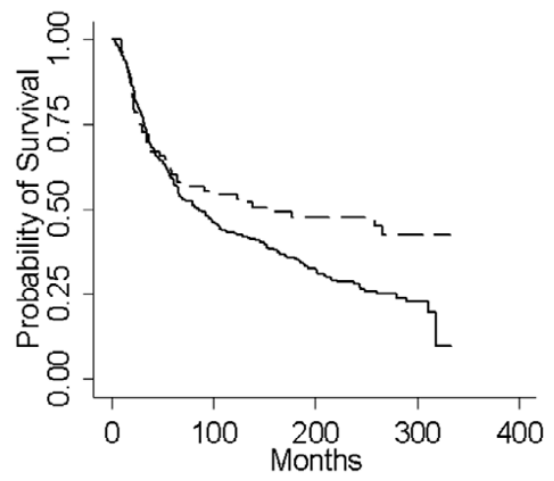

(c)

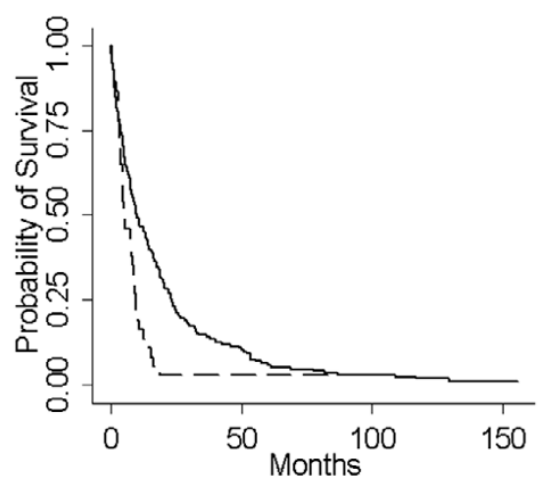

(e)

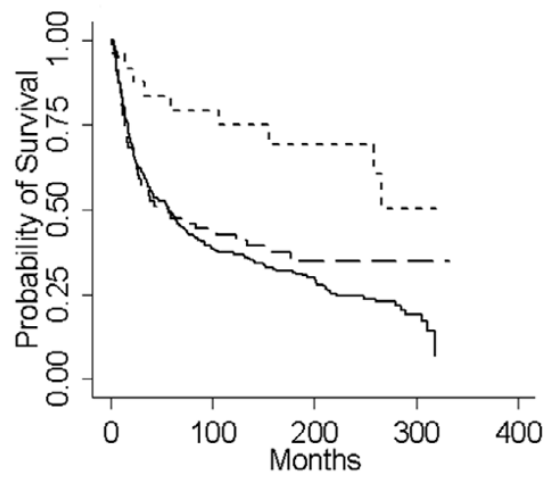

(b)

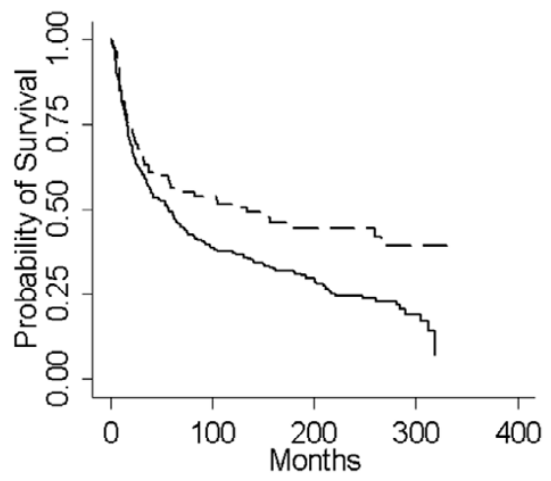

(d)

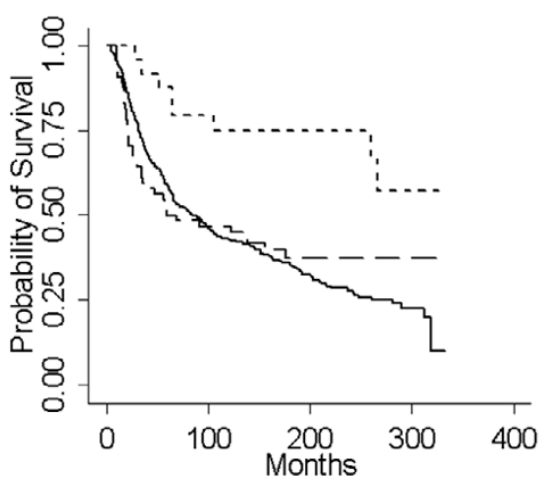

(f)

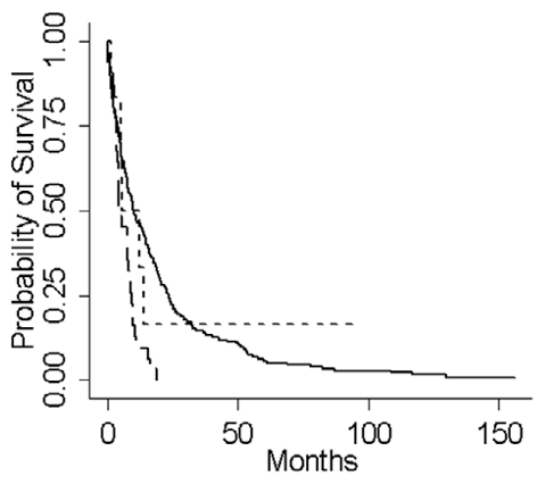

Long term survival in basal versus non-basal tumours. (a-c) Kaplan-Meier survival plots for basal (dashed line) versus non-basal (solid line) tumours. (a) Overall survival, (b) disease-free survival, and (c) survival from metastasis. (d-f) Kaplan-Meier survival plots for diffuse basal (short dashes) versus focal basal (long dashes) versus non-basal (solid line) tumours. (d) Overall survival, (e) disease-free survival, and (f) survival from metastasis.

on the long-term outcome in patients with grade III IDC-NST, a subgroup with a traditionally poor prognosis. We have specifically chosen a cohort of cases diagnosed historically as grade III ductal carcinomas, not including any special subtypes such as metaplastic breast carcinoma or medullary carcinoma, because this is the group of tumours in which the majority of basal cases seem to arise [5].
Terminology and definitions surrounding the concept of basal tumours are controversial, and a plethora of different markers and definitions have been employed to identify cases in clinical studies. Nielsen and colleagues [22] have proposed a definition based on ER, HER2, CK5/6, and EGFR (epidermal growth factor receptor) expression; however, even this definition does not show a perfect correlation with microarray data. Indeed, there is no accepted gold standard on which to 
Table 4

\begin{tabular}{|c|c|c|c|c|c|}
\hline \multirow[b]{2}{*}{ Prognostic factor } & \multirow[b]{2}{*}{ Level } & \multicolumn{2}{|c|}{ Overall survival } & \multicolumn{2}{|c|}{ Disease-free survival } \\
\hline & & Hazard ratio $(95 \% \mathrm{Cl})$ & $p$ value & Hazard ratio $(95 \% \mathrm{Cl})$ & $p$ value \\
\hline Basal & $\begin{array}{l}\text { CK14- } \\
\text { positive }\end{array}$ & $0.78(0.56-1.08)$ & 0.14 & $0.72(0.52-0.99)$ & 0.05 \\
\hline \multirow[t]{4}{*}{ Age group in years } & $<35$ & 1.0 & 0.0005 & 1.0 & 0.005 \\
\hline & $35-49$ & $0.86(0.54-1.37)$ & & $0.96(0.60-1.52)$ & \\
\hline & $50-64$ & $0.77(0.49-1.22)$ & & $0.80(0.51-1.26)$ & \\
\hline & $65+$ & $1.50(0.91-2.46)$ & & $1.43(0.87-2.36)$ & \\
\hline \multirow[t]{3}{*}{ Tumour size } & $\mathrm{p} 1$ & 1.0 & 0.052 & 1.0 & 0.042 \\
\hline & p2 & $1.45(0.84-2.48)$ & & $1.40(0.83-2.36)$ & \\
\hline & p3 & $1.87(1.06-3.31)$ & & $1.92(1.10-3.33)$ & \\
\hline Lymph node metastasis & Positive & $1.83(1.42-2.35)$ & $<0.0001$ & $1.81(1.42-2.32)$ & $<0.0001$ \\
\hline
\end{tabular}

Tumour sizes: $\mathrm{p} 1,<2 \mathrm{~cm} ; \mathrm{p} 2,2-5 \mathrm{~cm} ; \mathrm{p} 3,>5 \mathrm{~cm}$. Cl, confidence interval; CK14, cytokeratin 14.

assess any signature (for example, in a recent study [9], only $80 \%$ of tumours classified as HER2 by cDNA microarrays overexpressed HER2 at the immunohistochemical level). Given that there is currently no consensus terminology or internationally accepted definition (morphological or immunophenotypic) for basal-like tumours, we have employed CK14 alone to identify basal tumours in the present study. Our reasons for choosing a single marker are pragmatic: (a) limited material from this unique cohort of patients was available, and (b) CK14 is a marker that we have had considerable experience with and forms the basis for previous studies in the laboratory $[28,29,36]$. Furthermore, it has been demonstrated that CK14 expression correlates strongly with other 'basal' markers and that it identifies basal tumour proportions similar to those of other investigators (for example, CK5/6, CK17, and P-cadherin) $[21-26,32,33,35]$.

Our results have highlighted several important features of basal tumours as identified by CK14 expression. Relative to other grade III tumours, they are much more likely to be ERnegative and less likely to be axillary node-positive. They show lower rates of metastasis to the bone and liver but a higher rate of brain metastasis. Over the first 5 years after diagnosis, the relapse-free survival and OS appear to be similar to other grade III tumours, but their subsequent prognosis is much better. Given that in this study we compared grade III tumours only and that basal-like phenotype and 3+ expression of HER2 are more prevalent in this group but are inversely correlated $[9,22,39,47]$, it is likely that the non-basal-like tumours include a high prevalence of HER2-amplified tumours [47], which are reported to have an aggressive clinical behaviour. Further studies to directly compare the contribution of basal-like and HER2 phenotypes to survival of patients with grade III ductal carcinomas are warranted but are outside the remit of this study. The pattern of recurrence in basal tumours, with almost all recurrences occurring in the first 5 years, also differs from non-basal tumours, in which late relapse is widely recognised. Previous studies, many of which have a shorter median followup than that of our cohort of patients, have indicated that basal tumours usually have a very poor prognosis when compared to a mixture of grades I, II, and III basal keratin-negative breast tumours $[7,8,10,17,32,33]$. These observations are not necessarily inconsistent with this study, because our study does indicate a poor survival for patients with basal tumours for the first 5 years of follow-up.

The findings suggest the existence of two subgroups of basal carcinomas: one exhibiting early relapse and aggressive clinical course and a separate group that despite the traditionally poor prognostic indicators do not relapse. This would be consistent with the findings of our previous CGH analysis [28], which was carried out on a subset of the tumours examined in the present study and was able to split the basal tumours into two groups based on both their molecular genetic alterations and prognosis.

We found that traditional clinicopathological parameters could not discriminate between 'good' and 'bad' basal tumours. In addition, we found that none of the specific morphological features associated with the basal phenotype [36], such as central scar, high mitotic rates, pushing growth pattern, or necrosis, occurred with any significant difference between good and bad basal cases. However, the pattern of CK14 expression shows clear differences in prognosis. Those with a diffuse ( $>90 \%$; Figure $1 \mathrm{~b})$ staining pattern seem to fall largely into the good-prognosis group of tumours. A similar subclassification of basal tumours according to the expression of basal keratins into basal and basoluminal subtypes also suggested that tumours with a pure basal phenotype had a better prognosis [26]. 


\begin{tabular}{|c|c|c|c|c|c|c|}
\hline \multirow[t]{2}{*}{ Site of metastasis } & \multicolumn{2}{|c|}{ Number } & \multicolumn{2}{|c|}{$\begin{array}{c}\text { 5-year proportion free of } \\
\text { metastases }\end{array}$} & \multirow{2}{*}{$\begin{array}{l}\text { Hazard ratio } \\
(95 \% \mathrm{Cl})\end{array}$} & \multirow[t]{2}{*}{$p$ value } \\
\hline & Basal & Non-basal & Basal & Non-basal & & \\
\hline \multicolumn{7}{|l|}{ All sites } \\
\hline No & 51 & 169 & $59 \%$ & $55 \%$ & $0.65(0.48-0.88)$ & 0.005 \\
\hline Yes & 37 & 186 & & & & \\
\hline \multicolumn{7}{|l|}{ Bone } \\
\hline No & 74 & 245 & $85 \%$ & $73 \%$ & $0.49(0.28-0.86)$ & 0.01 \\
\hline Yes & 14 & 109 & & & & \\
\hline \multicolumn{7}{|l|}{ Liver } \\
\hline No & 76 & 265 & $86 \%$ & $77 \%$ & $0.53(0.29-0.97)$ & 0.035 \\
\hline Yes & 12 & 89 & & & & \\
\hline \multicolumn{7}{|l|}{ Brain } \\
\hline No & 75 & 327 & $85 \%$ & $93 \%$ & $1.92(0.27-1.01)$ & 0.051 \\
\hline Yes & 13 & 27 & & & & \\
\hline \multicolumn{7}{|l|}{ Lung/pleura } \\
\hline No & 65 & 261 & $73 \%$ & $77 \%$ & $0.92(0.58-1.46)$ & 0.72 \\
\hline Yes & 23 & 93 & & & & \\
\hline \multicolumn{7}{|l|}{ Skin } \\
\hline No & 79 & 316 & $87 \%$ & $90 \%$ & $0.94(0.45-1.95)$ & 0.87 \\
\hline Yes & 9 & 38 & & & & \\
\hline \multicolumn{7}{|l|}{ Pericardial/mediastinum } \\
\hline No & 84 & 342 & $94 \%$ & $97 \%$ & $1.23(0.39-3.83)$ & 0.72 \\
\hline Yes & 4 & 12 & & & & \\
\hline \multicolumn{7}{|l|}{ Nodes (non-regional) } \\
\hline No & 83 & 293 & $93 \%$ & $84 \%$ & $0.31(0.13-0.78)$ & 0.008 \\
\hline Yes & 5 & 61 & & & & \\
\hline
\end{tabular}

$\mathrm{Cl}$, confidence interval.

Because the majority of breast tumours in $B R C A 1$ germline mutation carriers are of basal type [27,34,41], our observations are also relevant to the prognosis in these women. Studies of prognosis in BRCA1 germline mutation carriers have been inconsistent; studies based on carriers identified through clinical testing in high-risk families have shown a relatively good prognosis, whereas studies based on testing of population series have shown a poor prognosis [48]. This apparent inconsistency could be explained by our results because cases undergoing clinical testing will tend to be identified some time after diagnosis when subsequent prognosis is good.
These concepts have important implications for patient management. This study confirms that there is a group of aggressive basal tumours that are currently not identified in routine diagnostic practice but that show a biological behaviour different from other grade III IDC-NST. They relapse early with short subsequent survival and notably carry a higher risk of brain metastases $[19,43]$. These tumours may need different (for example, platinum-based) [49] chemotherapy regimens or more aggressive therapeutic regimens and may need to be specifically identified in laboratory research designed to identify new therapeutic targets. 
It is also clear from these results that expression of basal markers alone cannot be used to indicate a tumour with poor prognosis. Indeed, it may be that some of the basal tumours with a better prognosis will require much less aggressive therapy and follow-up and that patients can be reassured of their long-term outlook despite being diagnosed with a grade III cancer.

\section{Conclusion}

This study shows that identifying basal tumours as a distinct group has real clinical relevance. They are relatively common, occurring in approximately $20 \%$ of grade III IDC-NST and approximately $10 \%$ of breast tumours overall. In the UK, with approximately 50,000 new breast tumours diagnosed each year, we may be missing some 5,000 basal tumours that carry distinct, but mixed, prognostic implications and that may respond differently to conventional chemotherapy regimens. The aim now is finding ways to further identify, characterise, and define 'good' and 'bad' basal tumours and to tailor management appropriately. Furthermore, these tumours may express distinct targets for novel therapeutic regimens, and research programmes should bear this in mind. Clinicopathological, therapeutic, and molecular genetic approaches will almost certainly all play a part in this task.

\section{Competing interests}

The authors declare that they have no competing interests.

\section{Authors' contributions}

LGF conceived the study, analysed the immunohistochemical markers, accrued and collated the data, carried out preliminary statistical analysis, supervised the statistical analysis, and drafted the manuscript. JSR-F analysed the immunohistochemical markers, accrued and collated the data, carried out preliminary statistical analysis, and drafted the manuscript. KR and $C E G$ curated the data. $\mathrm{CJ}$ and $\mathrm{AH}$ participated in the study design. DE supervised and reviewed the statistical analysis. SRL conceived the study, supervised the statistical analysis, and drafted the manuscript. All authors read and approved the final manuscript.

\section{Acknowledgements}

This study was supported in part by the Breakthrough Breast Cancer Research Centre and The Ludwig Institute for Cancer Research. This original work was presented in part as an oral presentation in the breast cancer pathology section at the 2004 annual United States and Canadian Academy of Pathology meeting in Vancouver, BC, Canada.

\section{References}

1. Ellis IO, Galea M, Broughton N, Locker A, Blamey RW, Elston CW: Pathological prognostic factors in breast cancer. II. Histological type. Relationship with survival in a large study with longterm follow-up. Histopathology 1992, 20:479-489.

2. Elston CW, Ellis IO: Pathological prognostic factors in breast cancer. I. The value of histological grade in breast cancer: experience from a large study with long-term follow-up. Histopathology 1991, 19:403-410.

3. Page DL, Jensen RA, Simpson JF: Routinely available indicators of prognosis in breast cancer. Breast Cancer Res Treat 1998, 51:195-208.
4. Pathology and Genetics of Tumours of the Breast and Female Genital Organs Edited by: Tavassoli FA, Devilee P. Lyon: IARC Press; 2003:10-112. 336-357

5. Page DL: Special types of invasive breast cancer, with clinical implications. Am J Surg Pathol 2003, 27:832-835.

6. Perou CM, Jeffrey SS, van de Rijn M, Rees CA, Eisen MB, Ross DT, Pergamenschikov A, Williams CF, Zhu SX, Lee JC, et al.: Distinctive gene expression patterns in human mammary epithelial cells and breast cancers. Proc Natl Acad Sci USA 1999, 96:9212-9217.

7. Sorlie T, Perou CM, Tibshirani R, Aas T, Geisler S, Johnsen H, Hastie T, Eisen MB, van de Rijn M, Jeffrey SS, et al.: Gene expression patterns of breast carcinomas distinguish tumor subclasses with clinical implications. Proc Natl Acad Sci USA 2001, 98:10869-10874.

8. Sorlie T, Tibshirani R, Parker J, Hastie T, Marron JS, Nobel A, Deng S, Johnsen H, Pesich R, Geisler S, et al:: Repeated observation of breast tumor subtypes in independent gene expression data sets. Proc Natl Acad Sci USA 2003, 100:8418-8423.

9. Rouzier R, Perou CM, Symmans WF, Ibrahim N, Cristofanilli M, Anderson K, Hess KR, Stec J, Ayers M, Wagner P, et al.: Breast cancer molecular subtypes respond differently to preoperative chemotherapy. Clin Cancer Res 2005, 11:5678-5685.

10. Sotiriou C, Neo SY, McShane LM, Korn EL, Long PM, Jazaeri A, Martiat $P$, Fox SB, Harris AL, Liu ET: Breast cancer classification and prognosis based on gene expression profiles from a population-based study. Proc Natl Acad Sci USA 2003, 100:10393-10398.

11. Murad TM, Scharpelli DG: The ultrastructure of medullary and scirrhous mammary duct carcinoma. Am J Pathol 1967 50:335-360.

12. Santini D, Ceccarelli C, Taffurelli M, Pileri S, Marrano D: Differentiation pathways in primary invasive breast carcinoma as suggested by intermediate filament and biopathological marker expression. J Pathol 1996, 179:386-391.

13. Gusterson BA, Warburton MJ, Mitchell D, Ellison M, Neville AM, Rudland PS: Distribution of myoepithelial cells and basement membrane proteins in the normal breast and in benign and malignant breast diseases. Cancer Res 1982, 42:4763-4770.

14. Heatley M, Maxwell $P$, Whiteside $C$, Toner P: Cytokeratin intermediate filament expression in benign and malignant breast disease. J Clin Pathol 1995, 48:26-32.

15. Dairkee $\mathrm{SH}$, Ljung BM, Smith $\mathrm{H}$, Hackett $\mathrm{A}$ : Immunolocalization of a human basal epithelium specific keratin in benign and malignant breast disease. Breast Cancer Res Treat 1987, 10:11-20.

16. Malzahn K, Mitze M, Thoenes M, Moll R: Biological and prognostic significance of stratified epithelial cytokeratins in infiltrating ductal breast carcinomas. Virchows Arch 1998, 433:119-129.

17. van de Rijn M, Perou CM, Tibshirani $R$, Haas $P$, Kallioniemi $O$, Kononen J, Torhorst J, Sauter G, Zuber M, Kochli OR, et al:: Expression of cytokeratins 17 and 5 identifies a group of breast carcinomas with poor clinical outcome. Am J Pathol 2002, 161:1991-1996.

18. Tsuda H, Morita D, Kimura M, Shinto E, Ohtsuka $Y$, Matsubara $O$, Inazawa J, Tamaki K, Mochizuki H, Tamai S, Hiraide H: Correlation of KIT and EGFR overexpression with invasive ductal breast carcinoma of the solid-tubular subtype, nuclear grade 3 , and mesenchymal or myoepithelial differentiation. Cancer Sci 2005, 96:48-53.

19. Tsuda H, Takarabe T, Hasegawa F, Fukutomi T, Hirohashi S: Large, central acellular zones indicating myoepithelial tumor differentiation in high-grade invasive ductal carcinomas as markers of predisposition to lung and brain metastases. $\mathrm{Am} \mathrm{J}$ Surg Pathol 2000, 24:197-202.

20. Tsuda H, Takarabe T, Hasegawa T, Murata T, Hirohashi S: Myoepithelial differentiation in high-grade invasive ductal carcinomas with large central acellular zones. Hum Pathol 1999, 30:1134-1139.

21. Reis-Filho JS, Simpson PT, Martins A, Preto A, Gartner F, Schmitt FC: Distribution of p63, cytokeratins $5 / 6$ and cytokeratin 14 in 51 normal and 400 neoplastic human tissue samples using TARP-4 multi-tumor tissue microarray. Virchows Arch 2003, 443:122-132

22. Nielsen TO, Hsu FD, Jensen $K$, Cheang M, Karaca G, Hu Z, Hernandez-Boussard T, Livasy C, Cowan D, Dressler L, et al.: Immunohistochemical and clinical characterization of the basal-like 
subtype of invasive breast carcinoma. Clin Cancer Res 2004, 10:5367-5374.

23. Carey LA, Perou CM, Livasy CA, Dressler LG, Cowan D, Conway $\mathrm{K}$, Karaca G, Troester MA, Tse CK, Edmiston S, et al:: Race, breast cancer subtypes, and survival in the Carolina Breast Cancer Study. JAMA 2006, 295:2492-2502.

24. Matos I, Dufloth $R$, Alvarenga M, Zeferino LC, Schmitt F: p63, cytokeratin 5 , and $P$-cadherin: three molecular markers to distinguish basal phenotype in breast carcinomas. Virchows Arch 2005, 447:688-694.

25. Laakso M, Loman N, Borg A, Isola J: Cytokeratin 5/14-positive breast cancer: true basal phenotype confined to BRCA1 tumors. Mod Pathol 2005, 18:1321-1328.

26. Laakso M, Tanner M, Nilsson J, Wiklund T, Erikstein B, KellokumpuLehtinen P, Malmstrom P, Wilking N, Bergh J, Isola J: Basoluminal carcinoma: a new biologically and prognostically distinct entity between basal and luminal breast cancer. Clin Cancer Res 2006, 12:4185-4191.

27. Lakhani SR, Reis-Filho JS, Fulford L, Penault-Llorca F, van der Vijver M, Parry S, Bishop T, Benitez J, Rivas C, Bignon YJ, et al:: Prediction of BRCA1 status in patients with breast cancer using estrogen receptor and basal phenotype. Clin Cancer Res 2005, 11:5175-5180.

28. Jones $C$, Ford $E$, Gillett $C$, Ryder K, Merrett S, Reis-Filho JS, Fulford LG, Hanby A, Lakhani SR: Molecular cytogenetic identification of subgroups of grade III invasive ductal breast carcinomas with different clinical outcomes. Clin Cancer Res 2004, 10:5988-5997.

29. Jones C, Nonni AV, Fulford L, Merrett S, Chaggar R, Eusebi V, Lakhani SR: CGH analysis of ductal carcinoma of the breast with basaloid/myoepithelial cell differentiation. $\mathrm{Br} J$ Cancer 2001, 85:422-427.

30. Jacquemier J, Padovani L, Rabayrol L, Lakhani SR, Penault-Llorca F, Denoux Y, Fiche M, Figueiro P, Maisongrosse V, Ledoussal V, et al: Typical medullary breast carcinomas have a basal/myoepithelial phenotype. J Pathol 2005, 207:260-268.

31. Tot T: The cytokeratin profile of medullary carcinoma of the breast. Histopathology 2000, 37:175-181.

32. Abd El-Rehim DM, Ball G, Pinder SE, Rakha E, Paish C, Robertson JF, Macmillan D, Blamey RW, Ellis IO: High-throughput protein expression analysis using tissue microarray technology of a large well-characterised series identifies biologically distinct classes of breast cancer confirming recent cDNA expression analyses. Int J Cancer 2005, 116:340-350.

33. Abd El-Rehim DM, Pinder SE, Paish CE, Bell J, Blamey RW, Robertson JF, Nicholson RI, Ellis IO: Expression of luminal and basal cytokeratins in human breast carcinoma. J Pathol 2004, 203:661-671.

34. Foulkes WD, Stefansson IM, Chappuis PO, Begin LR, Goffin JR, Wong N, Trudel M, Akslen LA: Germline BRCA1 mutations and a basal epithelial phenotype in breast cancer. J Natl Cancer Inst 2003, 95:1482-1485.

35. Rakha EA, Putti TC, Abd El-Rehim DM, Paish C, Green AR, Powe $\mathrm{DG}$, Lee $\mathrm{AH}$, Robertson JF, Ellis IO: Morphological and immunophenotypic analysis of breast carcinomas with basal and myoepithelial differentiation. J Patho/ 2006, 208:495-506.

36. Fulford LG, Easton DF, Reis-Filho JS, Sofronis A Gillett CE, Lakhani SR, Hanby A: Specific morphological features predictive for the basal phenotype in grade 3 invasive ductal carcinoma of breast. Histopathology 2006, 49:22-34.

37. Livasy CA, Karaca G, Nanda R, Tretiakova MS, Olopade OI, Moore DT, Perou CM: Phenotypic evaluation of the basal-like subtype of invasive breast carcinoma. Mod Pathol 2006, 19:264-271.

38. Reis-Filho JS, Milanezi F, Steele D, Savage K, Simpson PT, Nesland JM, Pereira EM, Lakhani SR, Schmitt FC: Metaplastic breast carcinomas are basal-like tumours. Histopathology 2006, 49:10-21.

39. Kim MJ, Ro JY, Ahn SH, Kim HH, Kim SB, Gong G: Clinicopathologic significance of the basal-like subtype of breast cancer: a comparison with hormone receptor and Her2/neu-overexpressing phenotypes. Hum Pathol 2006, 37:1217-1226.

40. Lakhani SR, Jacquemier J, Sloane JP, Gusterson BA, Anderson TJ, van de Vijver MJ, Farid LM, Venter D, Antoniou A, Storfer-Isser A, et al.: Multifactorial analysis of differences between sporadic breast cancers and cancers involving BRCA1 and BRCA2 mutations. J Natl Cancer Inst 1998, 90:1138-1145.
41. Turner NC, Reis-Filho JS, Russell AM, Springall RJ, Ryder K, Steele D, Savage K, Gillett CE, Schmitt FC, Ashworth A, et al.: BRCA1 dysfunction in sporadic basal-like breast cancer. Oncogene in press. 2006 Oct 2

42. Turner NC, Reis-Filho JS: Basal-like breast cancer and the BRCA1 phenotype. Oncogene 2006, 25:5846-5853.

43. Hicks DG, Short SM, Prescott NL, Tarr SM, Coleman KA, Yoder BJ, Crowe JP, Choueiri TK, Dawson AE, Budd GT, et al.: Breast cancers with brain metastases are more likely to be estrogen receptor negative, express the basal cytokeratin CK5/6, and overexpress HER2 or EGFR. Am J Surg Pathol 2006 30:1097-1104.

44. Gillett CE, Miles DW, Ryder K, Skilton D, Liebman RD, Springall $\mathrm{RJ}$, Barnes DM, Hanby AM: Retention of the expression of Ecadherin and catenins is associated with shorter survival in grade III ductal carcinoma of the breast. J Pathol 2001, 193:433-441.

45. King RJB, Redgrave S, Hayward JL, Millis RR, Rubens RD: The measurement of receptors for oestradiol and progesterone in human breast tumors. In Steroid Receptor Assays in Human Breast Cancer Edited by: King RJB. Cardiff: Omega Publishing; 1979:55-72.

46. Jensen EV, Green GL, Desombre ER: Immunochemical studies of estrogen receptors. Prog Clin Biol Res 1987, 249:283-305.

47. Banerjee S, Reis-Filho JS, Ashley S, Steele D, Ashworth A, Lakhani SR, Smith IE: Basal-like breast carcinomas: clinical outcome and response to chemotherapy. J Clin Pathol 2006, 59:729-735.

48. Chappuis PO, Rosenblatt J, Foulkes WD: The influence of familial and hereditary factors on the prognosis of breast cancer. Ann Oncol 1999, 10:1163-1170.

49. Turner N, Tutt $A$, Ashworth A: Hallmarks of 'BRCAness' in sporadic cancers. Nat Rev Cancer 2004, 4:814-819. 